\title{
Associations between HLA Class I alleles and the prevalence of nasopharyngeal carcinoma (NPC) among Tunisians
} Xin Li ${ }^{1}$, Nahla Ghandri ${ }^{2}$, Daniela Piancatelli ${ }^{3}$, Sharon Adams ${ }^{1}$, Deborah Chen1, Fu-Meei Robbins¹, Ena Wang1, Alessandro Monaco1, Silvia Selleri ${ }^{1}$, Noureddine Bouaouina ${ }^{2}$, David Stroncek ${ }^{1}$, Domenico Adorno $^{3}$, Lotfi Chouchane ${ }^{2}$ and Francesco M Marincola*1

\begin{abstract}
Address: ${ }^{1}$ Immunogenetics Section, Department of Transfusion Medicine, Clinical Center, National Institutes of Health, Bethesda, MD, 20892, USA, ${ }^{2}$ Laboratory of Molecular Immunology and Oncology, Faculty of Medicine of Monastir, Monastir, Tunisia and ${ }^{3} \mathrm{CNR}$, Institute for Organ Transplant and Immunocytology, L'Aquila, Italy

Email: Xin Li - Lixin2@cc.nih.gov; Nahla Ghandri - nahnouna@yahoo.fr; Daniela Piancatelli - d.piancatelli@itoi.cnr.it; Sharon Adams - SAdams1@cc.nih.gov; Deborah Chen - DSChen@cc.nih.gov; Fu-Meei Robbins - FRobbins@cc.nih.gov; Ena Wang - EWang@cc.nih.gov; Alessandro Monaco - monacoal@cc.nih.gov; Silvia Selleri - selleris@cc.nih.gov; Noureddine Bouaouina - noueddine.bouaouina@rns.tn; David Stroncek - DStroncek@cc.nih.gov; Domenico Adorno - d.adorno@itoi.cnr.it; Lotfi Chouchane - lotfi.chouchane@planet.tn; Francesco M Marincola* - FMarincola@cc.nih.gov

* Corresponding author
\end{abstract}

Published: 4 May 2007

Journal of Translational Medicine 2007, 5:22 doi:10.1 186/1479-5876-5-22
Received: 16 March 2007

Accepted: 4 May 2007

This article is available from: http://www.translational-medicine.com/content/5/I/22

(c) 2007 Li et al; licensee BioMed Central Ltd.

This is an Open Access article distributed under the terms of the Creative Commons Attribution License (http://creativecommons.org/licenses/by/2.0), which permits unrestricted use, distribution, and reproduction in any medium, provided the original work is properly cited.

\begin{abstract}
The high prevalence of nasopharyngeal cancer (NPC) in Southern Asia and Mediterranean Northern Africa suggests genetic predisposition among other factors. While Human Leukocyte Antigen (HLA) haplotypes have been conclusively associated with NPC predisposition in Asians, Northern African Maghrebians have been less intensely studied. However, low resolution serological methods identified weak positive associations with HLA-B5, BI 3 and $B \mid 8$ and a negative with HLA-BI4. Using sequence based typing (SBT), we performed a direct comparison of HLA class I frequencies in a cohort of 136 Tunisian patients with NPC matched for gender, age and geographical residence to 148 normal Tunisians. The bimodal age distribution of NPC in Maghrebians was also taken into account. HLA frequencies in normal Tunisians were also compared with those of Northern Moroccan Berbers (ME) to evaluate whether the Tunisian population in this study could be considered representative of other Maghrebian populations. HLA$\mathrm{BI} 4$ and $-\mathrm{Cw} 08$ were negatively associated with NPC (odd ratio $=0.09$ and 0.18 respectively, Fisher $\mathrm{P}_{2}$-value $=0.000 \mathrm{I}$ and $=0.003$ ). Moreover, positive associations were observed for HLA-B-18, $\mathrm{B} 5 \mathrm{I}$ (split of $-\mathrm{B} 5$ ) and $-\mathrm{B} 57$ ( $\mathrm{P}_{2}$-value $<0.025$ in all) confirming previous findings in Maghrebs. The HLA-BI 4/CW*08 haplotype frequency (HF) was 0.007 in NPC patients compared to 0.057 in both Tunisian $\left(\mathrm{OR}=0.12 ; \mathrm{P}_{2}\right.$-value $\left.=0.00 \mathrm{I}\right)$ and Moroccan controls. This study confirms several previous associations noted by serologic typing between HLA class I alleles and the prevalence of NPC in Maghrebians populations. In addition, we identified a putative haplotype rare in Tunisian patients with NPC that may serve as a genetic marker for further susceptibility studies.
\end{abstract}




\section{Background}

The prevalence of Epstein-Barr virus (EBV)-associated anaplastic nasopharyngeal carcinoma (NPC) might be partially dependent upon genetic background affecting predominantly certain ethnic groups ${ }^{1}$. Among them, some regions of Southern Asia suffer about a 100-fold higher prevalence compared with populations not at risk and this high prevalence is maintained upon immigration to Western Countries such as in the U.S. Chinese population Northern African populations (Algerians, Moroccans and Tunisians) referred to as Maghrebians also suffer increased prevalence of NPC which persists upon migration to low risk areas $[1,2]$ Although heterogeneity of viral strains, dietary, environmental and socio-economical variables have been implicated as predisposing factors, it is likely that genetic traits play a significant role at least in Asians [3,4].

Genetic predisposition of NPC is paralleled by a strong associations with some HLA class I alleles which have been extensively studied in the Asian population. Of them, HLA-A2, -B14, -B46 and -B58 predispose to the disease while HLA-A11 exercises a protective effect in Asians [5-12] Moreover, a meta-analysis confirmed a consistent association between HLA-A2, A11, B14, B46 and NPC [13]. With few exceptions [10,11]., most studies employed serologic HLA typing methods that cannot discriminate alleles within large serologic families [14]. Such discrimination, however, is critical since different ethnic groups display significant differences in frequency of HLA alleles within a serologic family with different capacity to bind and present epitopes that may be relevant to the immune defense against EBV-coded or other NPC-associated antigens. For instance, the HLA-A2 serologic family includes about 100 alleles [15] whose distribution is different among ethnic groups with HLA-A*0201 ( 90\%) and HLA-A*0205 ( 5\%) predominant among Caucasian and HLA-A*0203 ( 20\%) -A*0206 ( 15\%) and -A*0207 ( $\sim 40 \%)$ in Asians [16-19] Interestingly, sequence based typing (SBT) in Taiwanese identified a positive association between HLA-A*0207 (but not other HLA-A2 subtypes) and NPC [10]. This association was particularly strong when the observation was extended to the HLA-A*0207/ B*4601 haplotype. Since, chromosome $6 \mathrm{p}$, in particular $6 \mathrm{p} 21-23$, is characterized by unusually high gene density harboring gene clusters coding for several protein families besides HLA molecules [20], it remains unclear whether NPC/HLA associations reflect distinct antigen presentation potentials of various alleles or rather represent a marker for a susceptibility/protection locus in strong linkage disequilibrium with the HLA region [21].

Maghrebian populations have been less intensely studied at high-resolution SBT. Serological analyses reported positive associations between NPC and HLA: these included increased frequency of HLA-B5 in Algerians (38.2\% vs $24.4 \%$ ) [22], HLA-B13 in Tunisians (15.5\% vs 4\%) [23] and HLA-B18 in Moroccans, of which only the last was significant after correction for number of specificities tested (relative risk $=4.14$ ) [24]. In 1983, Heirat P et al. [22] reported in a cohort of patients with NPC from Algeria a lower frequency of HLA-Aw33 (3.9\% vs $16.8 \%$ ), -B14 (1.3\% vs $16 \%)$ and -DR4 (13.2\% vs $29.1 \%)$ in NPC compared with matched controls. After correction for the number of specificities tested, these differences were not statistically significant and were not pursued further. Subsequently, HLA-A*3301 and HLA-B*1402 were found to belong to the same ancestral haplotype [25]. Further studies done in other Maghrebians did not reproduce these findings. Independently, Mokni-Baizig N et al. [23] noted that the HLA-A23 allele was absent in NPC patients compared to an $18 \%$ frequency in non tumor-bearing Tunisians. This is interesting because HLA-A23 is part of an African extended haplotype that includes a -B14 allele (HLA-A*2301/HLA-B*1403) [26]. Moreover, Dardari R et al. [24] reported a significantly lower frequency of HLAA9 serologic family alleles in NPC patients compared with controls. Since the HLA-A9 serologic family includes HLAA23, this observation suggests that the reduced frequency of HLA-A9 reflects a lower frequency of the HLA-A*2301/ HLA-B*1403 haplotype. Thus, previous studies in Maghrebians suggest that HLA-B14 and HLA-A alleles linked to the HLA-B14 serological family may be under-represented in patients with NPC compared with normal controls. Conversely, HLA-B5, -B13 and -B18 could be associated with increased risk of NPC.

Molecular typing provides enhanced discrimination for population studies and large data bases have accumulated in African populations including Maghrebians [25-29] These studies, however, did not include Tunisians (TU). Therefore, the aim of this study was to 1) establish a high resolution SBT data base in normal Tunisians matched for gender, age and geographical residence to a similar cohort of NPC patients; 2) compare HLA allele and haplotype frequencies between normal healthy Tunisians and the previously characterized Northern Moroccan Berber population (ME) [28] to provide a broader frame for the interpretation of the results from the Tunisian study; 3 ) test the validity of the reported decreased prevalence of HLA-B14 and increased prevalence of HLA-B5, -B13 and -B18 in patients with NPC based on SBT-derived, high resolution information; 4) Find novel alleles and haplotypes associated with NPC in Tunisian that may serve as putative genetic markers for further susceptibility studies.

\section{Materials and methods Study population}

147 Patients with undifferentiated nasopharyngeal carcinoma were recruited from the Department of Radiation 
Oncology of Sousse Hospital, between 1991 and 2004. The patients with nasopharyngeal cancer had a mean age of $41.5 \pm 16$ years. The clinical stages ranged from II to IV (TNM classification, 1987). The diagnosis of cancer was confirmed by histopathology analyses. The histology was undifferentiated carcinoma (type III, WHO classification) in all cases $[30,31]$.

Patients were age and sex matched with 150 control subjects and selected from the same population living in the middle coast of Tunisia sharing the same environmental conditions. Control subjects having a mean age of $40 \pm$ 12.5 years were healthy blood donors having no evidence of any personal or family history of cancer (or other serious illness). In order to respect the Hardy-Weinberg conditions highly stringent criteria were used for recruitment. To avoid any consanguinity bias, both patients and control groups were formed with unrelated individuals.

The control Tunisian population data were also compared to an available database of SBT typing performed in a population from North Morocco [28] to provide a frame of reference for this study in the context of other previously studied Maghrebian populations.

\section{Specimen collection, preparation and HLA genotyping}

Blood samples were obtained from all subjects consenting to the collection of blood, [0] through venipuncture and processed for DNA preparation. Extracted DNA was shipped to the Department of Transfusion Medicine, Clinical Center; National Institutes of Health where the genotyping was performed. SBT of HLA class I loci was performed as previously described [32]. The primary PCR amplification reaction produced a $1.5 \mathrm{~kb}$ amplicon encompassing exon 1 through intron 4 of the HLA class I locus. All reagents necessary for primary amplification and sequencing were included in the HLA-A, HLA-B and HLA-C allele SEQR Sequenced Based Typing Kits (Abbott Diagnositics, Abbott Park, IL U.S.A.). After the primary amplification PCR products were purified from excess primers, dNTPs and genomic DNA using ExoSAP-IT (American Life Science, Cleveland, OH, U.S.A.). Each template was sequenced in the forward and reverse orientation for exon 2, exon 3 and exon 4 according to protocols supplied with the SBT kits. Excess dye terminators were removed from the sequencing products utilizing an ethanol precipitation method with absolute ethanol. The reaction products were reconstituted with $15 \mu \mathrm{l}$ of $\mathrm{Hi}$ $\mathrm{Di}^{\mathrm{TM}}$ Formamide (PE Applied Biosystems/Perkin-Elmer, Foster City, CA, U.S.A.) and analyzed on the ABI Prism* 3700 DNA Analyzer with Dye Set file: $Z$ and mobility file: DT3700POP6 [ET].

\section{Statistical analysis}

SBT information was used to compare our data base with recent reports on the prevalence of HLA alleles and haplotypes in African populations [25-29] The Hardy-Weinberg equilibrium was tested using the Guo and Thomson method [33], and gene diversity was estimated by maximum likelihood at each locus. Haplotype frequencies (HF) were estimated using an expectation-maximisation (EM) algorithm for multi-locus genotypic data when the gametic phase is not known employing the Arlequin population genetic software v3.01 [34,35] The Ewens-Watterson homozygosity test $[36,37]$ was used to examine the presence of selective forces influencing allelic diversity at each locus (balancing selection or directional selection). The significance was calculated by using the Ewens-Watterson test and Slatkin exact test [38,39]. HLA class I allele frequencies between Tunisians and Moroccans were compared using a $\chi^{2}$ analysis with Bonferroni correction. HLA class I (haplotipic) genetic diversity between the 2 populations was assessed by computing Fst genetic distance and the exact test of population differentiation using Arlequin. The most frequent 2 loci ( $\mathrm{Cw}-\mathrm{B}, \mathrm{A}-\mathrm{Cw}, \mathrm{A}-\mathrm{B})$ and class I $(\mathrm{A},-\mathrm{Cw},-\mathrm{B})$ haplotypes were described. Linkage disequilibrium (D) and relative $\mathrm{D}\left(\mathrm{D}^{\prime}\right)$ between two alleles at two different loci and their level of significance (p) for $2 \times$ 2 comparisons were calculated [40].

Comparisons between NPC and controls were performed first at the low resolution (two digit discrimination level) to compare our results with previously reported information based on low resolution serological typing. For this descriptive analysis data were simply compared using a 2 $\times 2$ comparison without correction for number of tests. Further, SBT based comparisons between NPC and control populations were performed using allele frequencies and haplotypes calculated with the statistical tests discussed in the previous paragraph.

\section{Results \\ HLA frequencies among non-tumor bearing healthy Tunisians (TU)}

To our knowledge no reports are available on SBT-defined HLA class I frequencies among healthy Tunisians. However, extensive information exists on other African/Maghrebian populations [25-29] We, therefore, first analyzed HLA class I frequencies in Tunisian in the context of available information in other Maghrebian populations. In particular, we performed a direct comparison with Piancatelli D. et al [28] SBT data on Moroccans.

Of the 150 samples obtained from normal control subjects only 147 HLA-A, 148 HLA-B and 147 HLA-Cw locus typings could be performed due to insufficient quantity or quality of the recovered genomic DNA in the remaining cases. Because of the recognized bimodal age distribution 
of NPC in Tunisia an effort was made to collect DNA representative of all age groups in the control population (Figure 1). The allele and haplotype frequencies for the HLA class I loci in the Tunisian population compared to Moroccan are reported in Tables 1, 2, 3. The Tunisian population was in Hardy-Weinberg equilibrium for all loci (HLA-A, $\mathrm{p}=0.568 \pm 0.000$; HLA-B, $\mathrm{p}=0.505 \pm 0.000$; HLA-Cw, $p=0.297 \pm 0.000)$; the allelic distribution showed a very high level of gene diversity: HLA-A 0.94; HLA-B 0.96 and HLA-Cw 0.90. In the Moroccan population, these values were slightly lower for HLA-A (0.92) and HLA-B (0.95), and not different for HLA-Cw. Population comparisons showed that the two populations were not significantly different (Fst p value: 0.189 ) and no sta-

\section{A}

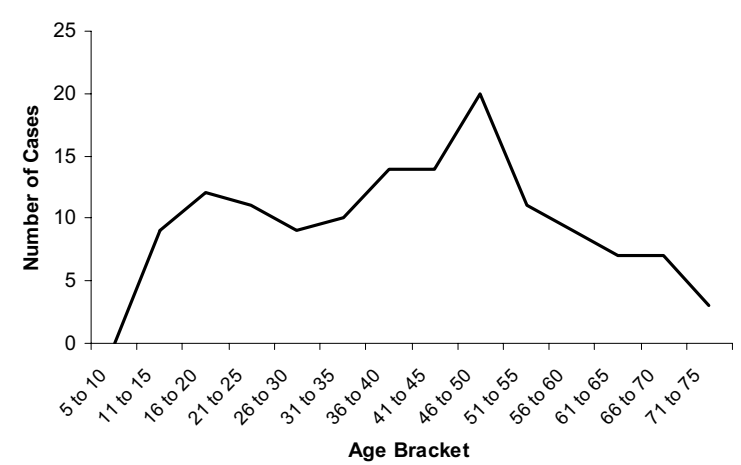

tistically significant differences were observed in allele frequencies between the two populations (Table 1).

By comparing in Tunisians the observed homozygosity $\mathrm{F}$ values with those expected under the Ewens-Watterson neutral model, a tendency toward balancing selection was observed, (observed $\mathrm{F}$ less than that expected under neutrality) although no significant difference in homozygosity was found (A locus: observed F: 0.068; expected F: 0.090; B locus: observed F: 0.048; expected F: 0.056; Cw locus: observed F: 0.101; expected F: 0.124).

\section{Single locus analysis}

A total of 35 HLA-A, 51 HLA-B and 24 HLA-Cw alleles were observed in Tunisians. The most frequently detected

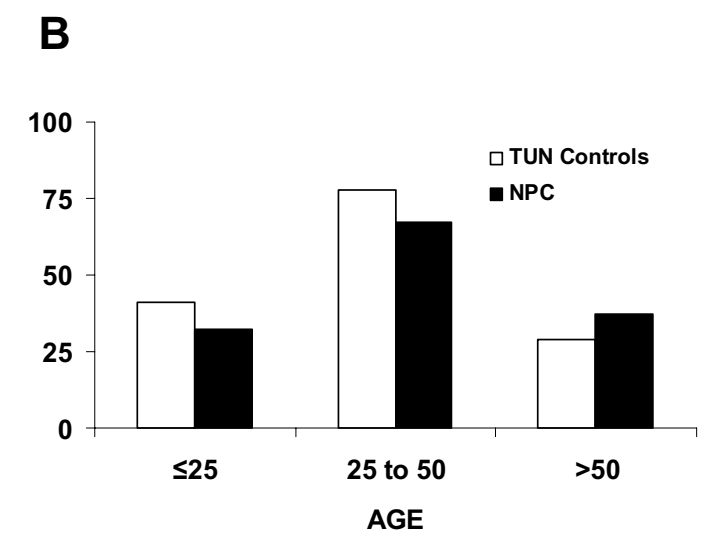

\begin{tabular}{c|ccc|ccc}
\hline & \multicolumn{3}{|c|}{ Control } & \multicolumn{3}{c}{ NPC } \\
& Total(\%) & Male(\%) & Female(\%) & Total(\%) & Male(\%) & Female(\%) \\
\hline$\leq 25$ & 41 & $30(0.73)$ & $11(0.27)$ & 32 & $17(0.53)$ & $15(0.47)$ \\
$25-50$ & 78 & $53(0.68)$ & $25(0.32)$ & 67 & $48(0.72)$ & $19(0.28)$ \\
$\geq 50$ & 29 & $20(0.69)$ & $9(0.31)$ & 37 & $27(0.73)$ & $10(0.27)$ \\
Total & 148 & 103 & 45 & 136 & 92 & 44 \\
\hline
\end{tabular}

\section{Figure I}

A: age distribution of the 136 patients with NPC whose DNA was a sufficient quality to yields informative typing results. Age is shown in 5 years brackets to underline the bi-modal distribution of NPC prevalence in Tunisian reflected by the population studied. B: Age distribution of patients with NPC (black bars) and normal TU controls (white bars) separated according to recognized brackets of prevalence: precocious NPC ( 10 to 25 years), middle age NPC (26 to 50) and late onset NPC (> 50 years of age) (lower panel). C: age distribution of patients with NPC and normal TU controls according to age and gender. 
Table I: HLA-A, -B and -Cw allele frequencies in ME and TU

\begin{tabular}{|c|c|c|c|c|c|c|c|c|}
\hline \multicolumn{9}{|c|}{ HLA-A allele (ME $\mathrm{n}=73 ; \mathrm{TU} \mathrm{n}=147$ ) } \\
\hline & ME & TU & & ME & TU & & $\mathrm{ME}$ & TU \\
\hline A*0I0I0I & 0.137 & 0.088 & A*110101 & 0.048 & 0.030 & A*330I & 0.055 & 0.031 \\
\hline A*0102 & 0 & 0.003 & $A * 230 I$ & 0.082 & 0.078 & $A * 3303$ & 0 & 0.01 \\
\hline$A^{*} 0103$ & 0 & 0.007 & A*24020I & 0.062 & 0.037 & A*33new* & 0 & 0.003 \\
\hline$A * 020101$ & 0.178 & 0.173 & $A * 250101$ & 0.007 & 0.007 & $A * 3402$ & 0.021 & 0.01 \\
\hline$A^{*} 0202$ & 0 & 0.034 & $A * 260 I$ & 0.007 & 0.031 & $A * 3601$ & 0 & 0.003 \\
\hline$A * 0205$ & 0 & 0.024 & $A * 2902$ & 0.041 & 0.061 & $A^{*} 6601$ & 0.021 & 0.02 \\
\hline$A * 0212$ & 0 & 0.003 & $A * 3001$ & 0.014 & 0.031 & $A * 680101$ & 0.021 & 0.031 \\
\hline$A * 0285$ & 0 & 0.003 & $A * 3002$ & 0.089 & 0.044 & $A * 680102$ & 0.021 & 0.014 \\
\hline$A^{*} 02$ new* & 0 & 0.003 & $A * 3004$ & 0.007 & 0.003 & $A * 680201$ & 0.048 & 0.054 \\
\hline$A * 030101$ & 0.034 & 0.068 & $A * 3010$ & 0 & 0.003 & $A * 740 \mathrm{I}$ & 0.014 & 0.003 \\
\hline$A^{*} 030103$ & 0 & 0.003 & $A * 310102$ & 0.021 & 0.024 & $A^{*} 8001$ & 0 & 0.007 \\
\hline$A^{* 0302}$ & 0.041 & 0.017 & $A * 320 I$ & 0.034 & 0.034 & & & \\
\hline \multicolumn{9}{|c|}{ HLA-B allele (ME $n=69 ;$ TU $n=148)$} \\
\hline & ME & TU & & ME & TU & & ME & TU \\
\hline B*07020I & 0.022 & 0.041 & $B * 3508$ & 0 & 0.014 & $B * 490 I$ & 0.051 & 0.027 \\
\hline$B * 0705,06$ & 0.007 & 0.003 & $B * 3701$ & 0.007 & 0.007 & $B * 5001$ & 0.073 & 0.139 \\
\hline $\mathrm{B} * 080 \mathrm{I} * *$ & 0.087 & 0.064 & $B * 380 I$ & 0.014 & 0.020 & $B * 5002$ & 0.043 & 0.014 \\
\hline $\mathrm{B} * 1302^{\circ \circ}$ & 0 & 0.017 & $B * 390602$ & 0 & 0.003 & $B * 510101,02$ & 0.043 & 0.054 \\
\hline$B * 1401$ & 0.014 & 0.010 & $B * 3910$ & 0.007 & 0.007 & $B * 5108$ & 0 & 0.003 \\
\hline$B * 1402$ & 0.036 & 0.054 & $B * 3920$ & 0 & 0.003 & $B * 520101,02$ & 0.007 & 0.024 \\
\hline$B * 1403$ & 0 & 0.010 & $B * 400 I$ & 0 & 0.010 & $B^{*} 530 I^{\wedge \wedge}$ & 0.014 & 0.024 \\
\hline$B^{*} 150101$ & 0 & 0.014 & $B * 4002$ & 0.007 & 0.003 & $B * 5303$ & 0 & 0.003 \\
\hline$B * 1503$ & 0.014 & 0.017 & $B * 4101$ & 0 & 0.017 & B*53new* & 0 & 0.003 \\
\hline$B * 1510$ & 0 & 0.004 & $B * 4102$ & 0.065 & 0.020 & $B * 5501$ & 0 & 0.003 \\
\hline$B^{*} 1516$ & 0 & 0.017 & $B * 420 I$ & 0 & 0.017 & $B * 570101$ & 0.014 & 0.003 \\
\hline$B^{*}|5| 70 \mid$ & 0 & 0.007 & $B * 4202$ & 0.007 & 0.007 & $B * 5702$ & 0 & 0.003 \\
\hline$B^{*} 180101$ & 0.051 & 0.023 & $B * 4402$ & 0.094 & 0.047 & $B * 570302$ & 0.007 & 0 \\
\hline$B * 2702$ & 0.007 & 0.007 & B*44030I & 0.116 & 0.071 & $B * 5801$ & 0.014 & 0.027 \\
\hline$B * 2703$ & 0.007 & 0 & $B * 440302$ & 0.007 & 0 & $B * 5802$ & 0.007 & 0.003 \\
\hline$B * 2705,13^{\wedge}$ & 0.021 & 0.010 & $B * 4405$ & 0 & 0.003 & $B * 730 I$ & 0 & 0.007 \\
\hline B*350101,42 & 0.043 & 0.027 & $B * 4427$ & 0 & 0.007 & $B * 780 I$ & 0.014 & 0 \\
\hline$B * 3502$ & 0.007 & 0.017 & $B * 450 I$ & 0.043 & 0.047 & & & \\
\hline$B * 3503$ & 0.014 & 0.014 & $\mathrm{~B} * 47010 \mathrm{I}$ & 0.007 & 0.003 & & & \\
\hline \multicolumn{9}{|c|}{ HLA-Cw allele $(M E n=63 ; T U n=147)$} \\
\hline & ME & TU & & ME & TU & & ME & TU \\
\hline $\mathrm{Cw}^{*} 0102$ & 0 & 0.007 & $\mathrm{Cw} * 0602$ & 0.183 & 0.218 & $C w^{*}|4020|$ & 0.008 & 0.027 \\
\hline$C w^{* 020202 * * *}$ & 0.095 & 0.054 & $C w^{*} 0701,06^{\circ}$ & 0.183 & 0.129 & $C w^{*} \mid 50201$ & 0.016 & 0.034 \\
\hline$C w^{*} 0210$ & 0.016 & 0.017 & $\mathrm{Cw} * 07020 \mathrm{I}$ & 0.032 & 0.054 & $C w * 150501,02$ & 0.016 & 0.014 \\
\hline $\mathrm{Cw}^{* 0302}$ & 0 & 0.010 & $C w * 0704,071 \mathrm{I}$ & 0.016 & 0.010 & $C w^{*} 1601$ & 0.032 & 0.044 \\
\hline$C w * 030301$ & 0 & 0.003 & $C w * 0802$ & 0.056 & 0.058 & $C w^{*} 1602$ & 0.016 & 0.007 \\
\hline $\mathrm{Cw}^{*} 030401,02^{\circ 00}$ & 0 & 0.014 & $C w * 120201,02$ & 0.008 & 0.024 & $C w^{*} \mid 6040 I$ & 0 & 0.003 \\
\hline$C w^{*} 040101$ & 0.159 & 0.126 & $C w^{*}|2030|$ & 0.008 & 0.044 & $C w^{*} \mid 701,02,03^{\wedge \wedge \wedge}$ & 0.07 I & 0.051 \\
\hline $\mathrm{Cw}^{*} 0501,03$ & 0.087 & 0.048 & $C w^{*} 12 n e w^{*}$ & 0 & 0.003 & & & \\
\hline
\end{tabular}

Alleles having a frequency $>5 \%$ are in bold. ${ }^{\circ}$ Including $\mathrm{CW} * 070101,02 ; * *$ Two samples in this group were assigned as $\mathrm{B} * 080101 ;{ }^{\circ}$ One sample in this group was assigned as $B^{*} 130201$; ^ Two samples in this group were assigned as $B * 270502$ (IME, ITU); ${ }^{\wedge}$ Two samples in this group were

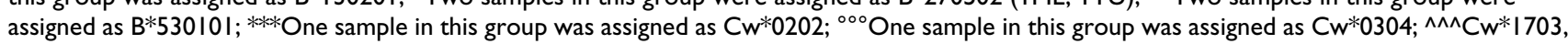
af $=0.063$ in ME.

Not discriminated alleles due to polymorphisms outside the assayed exons are listed separated by ",". Nomenclature was updated until the sixth digit; seventh and eighth digits were not included in the table. In case of ambiguous allele combinations, the most frequent allele combination was included in the analysis.

No statistically significant differences were identified in any comparison between the Tunisian and Moroccan cases. 
Table 2: Most common (frequency > 2\%) HLA-A/B, Cw/B and Cw/B two-locus haplotypes in TU

\begin{tabular}{|c|c|c|c|c|c|c|}
\hline \multirow[t]{2}{*}{ Haplotype } & \multicolumn{5}{|c|}{ TUNISIANS } & \multirow[t]{2}{*}{ Present in:* } \\
\hline & $\mathrm{HF}$ & $\mathrm{D} \times 100$ & $D^{\prime}$ & $\chi^{2}$ & $P$ & \\
\hline \multicolumn{7}{|l|}{ A/B } \\
\hline$A * 020101 B * 5001$ & 0.046 & 2.20 & 0.19 & 8.30 & $<0.01$ & Caucasians, Hispanics, Tunisians' \\
\hline$A * 020101 B * 440201$ & 0.037 & 2.90 & 0.74 & 38.00 & $<0.001$ & Caucasians, Blacks \\
\hline$A * 2301 B * 5001$ & 0.030 & 1.90 & 0.29 & 13.00 & $<0.001$ & \\
\hline$A * 6802 B * 1402$ & 0.024 & 2.10 & 0.41 & 50.00 & $<0.001$ & Mixed \\
\hline$A * 020101 B * 510101$ & 0.024 & 1.50 & 0.33 & 8.70 & $<0.05$ & Caucasians, Hispanics, Blacks, Tunisians 1 \\
\hline \multicolumn{7}{|l|}{ Cw/B } \\
\hline$C w * 0602 \mathrm{~B} * 500 \mathrm{I}$ & 0.122 & 9.10 & 0.84 & 120.00 & $<0.001$ & Hispanics \\
\hline$C W * 0701 \mathrm{~B} * 080 \mathrm{I}$ & 0.047 & 3.80 & 0.69 & 65.00 & $<0.001$ & Caucasians, Hispanics, Blacks, Tunisians' \\
\hline$C w * 0501 B * 4402$ & 0.041 & 3.90 & 0.87 & 22.00 & $<0.001$ & Caucasians, Hispanics, Blacks, Tunisians' \\
\hline$C w * 0802 B * \mid 402$ & 0.037 & 3.40 & 0.66 & 120.00 & $<0.001$ & Caucasians, Hispanics, Blacks, Tunisians 1 \\
\hline$C w * 0602 B * 4501$ & 0.034 & 2.40 & 0.65 & 22.00 & $<0.001$ & Black \\
\hline Cw*0702 B*07020I & 0.034 & 3.10 & 0.80 & 140.00 & $<0.001$ & Caucasians, Blacks, Orientals \\
\hline$C w * 1502 B * 510101$ & 0.034 & 3.20 & 1.00 & 180.00 & $<0.001$ & Caucasians, Hispanics, Tunisians' \\
\hline$C w * 0701 B * 4901$ & 0.027 & 2.30 & 0.99 & 54.00 & $<0.001$ & Hispanics, Blacks, Tunisians 1 \\
\hline$C w * 0202 B * 440301$ & 0.027 & 2.20 & 0.33 & 32.00 & $<0.001$ & \\
\hline $\mathrm{Cw}^{*} \mid 601 \mathrm{~B} * 440301$ & 0.027 & 2.40 & 0.58 & 59.00 & $<0.001$ & Caucasians, Hispanics, Tunisians' \\
\hline$C w^{*} \mid 202 B * 520101$ & 0.024 & 2.30 & 1.00 & 30.00 & $<0.001$ & Hispanics, Orientals, Tunisians' \\
\hline$C W^{*} 1701,03 \mathrm{~B} * 4102$ & 0.020 & 1.90 & 1.00 & 110.00 & $<0.001$ & Very common \\
\hline$C W * 040101 B * 3501$ & 0.020 & 1.70 & 0.70 & 28.00 & $<0.001$ & Caucasians, Hispanics, Blacks, Tunisians' \\
\hline $\mathrm{Cw}^{*} 040101 \mathrm{~B} * 530 \mathrm{I}$ & 0.020 & 1.70 & 0.81 & 33.00 & $<0.001$ & Hispanics, Blacks \\
\hline$C w * 12030|B * 380|$ & 0.020 & 1.90 & 1.00 & 130.00 & $<0.001$ & Caucasians, Hispanic, Tunisians ${ }^{\prime}$ \\
\hline \multicolumn{7}{|l|}{$\mathbf{A} / \mathbf{C w}$} \\
\hline$A * 020101 C_{w} * 0602$ & 0.063 & 2.50 & 0.19 & 7.80 & $<0.01$ & \\
\hline$A * 2301 \mathrm{Cw} * 0602$ & 0.036 & 1.90 & 0.31 & 7.70 & $<0.01$ & \\
\hline$A * 030101 C^{*} * 0602$ & 0.035 & 2.00 & 0.38 & 11.00 & $<0.001$ & \\
\hline$A * 010101 C_{w} * 040101$ & 0.034 & 2.30 & 0.30 & 18.00 & $<0.001$ & Blacks \\
\hline$A * 020101 C_{W} * 0501$ & 0.033 & 2.50 & 0.62 & 28.00 & $<0.001$ & \\
\hline
\end{tabular}

In bold: haplotypes shared with ME. Other haplotypes (in italics) are shared but were not in linkage $(\mathrm{p}=\mathrm{ns})$ or were present at low frequency $(<$ $1.5 \%$ ) in ME.

HF: haplotype frequency; SD: standard deviation; Dx100: linkage disequilibrium multiplied by 100; D': relative linkage disequilibrium; ChiSQ: chisquare values

* According to the allele frequency worldwide population database $[42,43]$.

alleles in Tunisians and Moroccans were: HLA$\mathrm{A}^{*} 020101$ (TU:17.3\%, ME:17.8\%), A*010101 (TU:8.8\%, ME:13.7\%), A*2301 (TU:7.8\%, ME:8.2\%), HLAB*5001(TU:13.9\%， ME:7.3\%)， B*440301(TU:7.1\%， ME:11.6\%), B*0801(TU:6.4\%, ME:8.7\%), HLA$\mathrm{CW}^{*} 0602$ (TU:21.8\%, ME:18.3\%), Cw*040101 (TU:12.6\%, ME:15.9\%) and $\mathrm{Cw}^{*} 07$ group (TU:19.3\%, $\mathrm{ME}: 18.4 \%)$.

Noteworthy was the presence of rare alleles in Tunisians, as classified according to the National Marrow Donor Program [41], such as B*5303 (originally identified in Hispanics but present also in Africans and Caucasians) and $\mathrm{A}^{*} 0285$ (Caucasian) and uncommon alleles present in Africans, such as $\mathrm{A}^{*} 3010$ (identified in Moroccans), $A^{*} 0103, A^{*} 3004, A^{*} 3601, A^{*} 8001, B^{*} 1403, B^{*} 4202$,
$\mathrm{B}^{*} 5702, \mathrm{Cw}^{*} 0210$ (present in Moroccans), A*030103, $\mathrm{B}^{*} 4405, \mathrm{~B} * 4427, \mathrm{~B} * 5108, \mathrm{~B}^{*} 7301, \mathrm{Cw}^{*} 1604$ (present in Caucasians), A*0212, B*390602, B*5303 (present in Hispanics) and $B^{*} 3920$ (present in Blacks). Although not significant, a lower frequency of $B^{*} 44$, with a wider number of alleles (some of which uncommon), was found in Tunisians compared to Moroccans (12.8\% vs. $21.7 \%$, p = ns), with a frequency similar to South Africans (Zulu $12 \%$, Cameroon $8.7 \%$ ). The HLA-B*50 allele frequencies were high in Tunisians (15.3\%) as in Moroccans $(11.6 \%)$ and in accordance with previously reported information about Tunisians of mixed origin (10\%) [42]. Many allele groups showed a high variability (4-6 alleles, $A^{*} 02, A^{*} 30, B^{*} 15$, $\left.\mathrm{B}^{*} 35, \mathrm{~B} * 44\right)$. For instance, the HLA-B*15 group included the $-\mathrm{B}^{*} 1503$ and $-\mathrm{B}^{*} 1510$ alleles, that are present at high frequency in Sub-Saharan Africa. Overall, this data sup- 
Table 3: Most common HLA-A, -Cw, -B haplotypes in TU and ME.

\begin{tabular}{lcc}
\hline Haplotypes & TU & ME \\
\cline { 2 - 3 } & HF SD & HF SD \\
\hline A020I Cw0602 B5001 & $0.054 \pm 0.013$ & $0.040 \pm 0.019$ \\
A0201 Cw0501, 03 B4402 & $0.034 \pm 0.011$ & $(0.008 \pm 0.107)$ \\
A2301 Cw0602 B5001 & $0.024 \pm 0.009$ & - \\
A0201 Cw040101 B4403 & $(0.007 \pm 0.005)$ & $0.032 \pm 0.016$ \\
A2301 Cw040101 B4403 & $(0.007 \pm 0.005)$ & $0.032 \pm 0.014$ \\
A0101 Cw0501, 03 B4402 & - & $0.032 \pm 0.017$ \\
\hline
\end{tabular}

Standard deviations (SD) have been approximated by 400 bootstrap replicates. In bold: shared haplotypes. In parenthesis: haplotype present at low frequency in one of the two populations.

port the concept that Tunisians like other Maghrebian populations maintain a Northern African genetic identity which, however, includes traits derived from Sub-Saharan African [29] as well as Spanish/European influence [27]. The higher level of differentiation present in Moroccans, expressed by a reduced number of alleles compared to TU, can be a genetic demonstration of a higher isolation of this ethnic group.

\section{Extended haplotype analysis}

One hundred and eighty different haplotypes were calculated in Tunisians. Data on haplotypes are shown in table 2 ( 2 loci) and table 3 (3 loci). The most common class I haplotypes were $\mathrm{A}^{*} 0201-\mathrm{B}^{*} 5001-\mathrm{Cw}^{*} 0602$, shared by Tunisians (haplotype frequency; $\mathrm{hf}=0.054$ ) and Moroccans $(\mathrm{hf}=0.040)$ and also present in Hispanics [43] (Table 3), and $\mathrm{A}^{*} 0201-\mathrm{B}^{*} 4402-\mathrm{CW}^{*} 05$, present in Hispanics, Africans and Caucasians [43,42]. The A*2301$\mathrm{B}^{*} 5001-\mathrm{Cw}^{*} 0602$ was not found in other populations, like the $\mathrm{A}^{*} 2301-\mathrm{B} * 5001$ 2-loci association. Many Cw-B haplotypes, in strong linkage disequilibrium, are common haplotypes found in Hispanic, Caucasians, African and African American (Black) populations, and have been detected in other Tunisians [42]. Most haplotypes were shared between Tunisians and Moroccans (Table 2 and 3, in bold). Exceptions were represented by $A^{*} 2301$ B*5001 and B4403-Cw0202, not found in other populations, and there were also not present $\left(A^{*} 2301-B * 5001\right)$ or present but in no significant linkage disequilibrium (B4403-Cw0202) in Moroccans.

\section{HLA class I frequencies in Tunisian patients with NPC}

Of the 147 samples obtained from Tunisian subjects with NPC only 135 HLA-A, 135 HLA-B and 136 HLA-Cw locus typings could be carried out due to insufficient quantity or quality of the recovered genomic DNA (Figure 1). The age distribution of the cohort of NPC patients in this study well reflected the recognized bimodal age distribution of NPC in Tunisia. Indeed, the study included 32 patients with NPC that were 25 year old or younger corresponding to a frequency of $23 \%$ identical to the frequency reported for this age group by Daoud J et al. [44].

To compare our results with previously reported studies on NPC in Maghrebian populations, we first analyzed allele frequencies at a low resolution (two digits) level that more closely approximate the serological nomenclature. Simple two by two comparison tables identified HLA-B18, -B51 and -B57 to be associated with a predisposition to develop NPC (Table 4). On the contrary, HLAB14 and Cw-08 were associated with a decreased risk of developing NPC. The haplotype frequency was strongly reduced in patients with NPC. At the phenotype level, 2 of 136 patients with NPC carried the HLA Cw*0802-B*1402 haplotype $(1.47 \%)$ while 11 of $148(7.4 \%)$ Tunisian controls carried this haplotype (Fisher's test $\mathrm{p}_{2}$-value $<0.001$ ). With the exception of HLA-Cw-08, these findings specifically reproduced associations that had been previously described in Maghrebian populations $[22,24]$ Thus, these results encouraged an in depth analysis of the HLA frequencies in patients with NPC from Tunisia at the high resolution level.

\section{Extended haplotype analysis in Tunisian patients with NPC}

The comparisons with the normal Tunisian and Moroccan populations were performed only for haplotypes found in Tunisians and/or patients with NPC (Table 5). Several associations were noted between NPC prevalence and HLA haplotypes. HLA-B* 1801 was positively associated with the prevalence of NPC at the allele and haplotype level (specific NPC haplotype: $\mathrm{A}^{*}$ 020101-Cw*0701B*180101, absent in Tunisians and Moroccans). The haplotype $\mathrm{Cw}^{*} 0501-\mathrm{B} 180101$ was observed in Moroccans and, therefore, it may be less specific; HLA-B*570101 was also positively associated at the allele and haplotype level (specific NPC haplotype: $\mathrm{A}^{*} 010101-\mathrm{Cw}^{*} 0602-$ $\mathrm{B}^{*} 570101$, absent in Tunisians and Moroccans). Finally, HLA B*510101 was associated with an increased risk of developing NPC only at the allele but not the haplotype level. 
Table 4: Significant (Fisher's test $p_{2}<0.05$ ) allele associations with NPC

\begin{tabular}{ccccccc}
\hline HLA allele & NPC cases (\%) & Control subjects (\%) & OR & $95 \%$ Cl & Ref \\
\hline Cw08 & $1.10(3 / 272)$ & $5.74(17 / 296)$ & 0.18 & $0.052-0.618$ & 0.003 & - \\
BI4 & $0.74(2 / 270)$ & $7.43(22 / 296)$ & 0.09 & $0.021-0.388$ & 0.0001 & {$[22]$} \\
BI4-Cw08 & $0.74(2 / 270)$ & $5.74(17 / 296)$ & 0.12 & $0.027-0.519$ & 0.001 & - \\
B5I & $11.11(30 / 270)$ & $5.74(17 / 296)$ & 1.98 & $1.067-3.679$ & 0.025 & {$[22]$} \\
B57 & $3.70(10 / 270)$ & $0.68(2 / 296)$ & 5.48 & $1.190-25.224$ & 0.017 & {$[22]$} \\
B18 & $6.67(18 / 270)$ & $2.36(7 / 296)$ & 2.85 & $1.173-6.941$ & 0.014 & {$[24]$} \\
\hline
\end{tabular}

N.B. 136 typing could be performed for the HLA-Cw locus in patient with NPC while only 135 could be performed in the same patients for the HLA-A and -B loci.

SBT identified several sub-haplotypes including an HLA$\mathrm{B}^{*} 14$ allele $\left(\mathrm{CW}^{*} 0802-\mathrm{B}^{*} 1402, \mathrm{~A}^{*} 6802-\mathrm{B}^{*} 1402\right.$ and $\left.\mathrm{A}^{*} 1101-\mathrm{CW}^{*} 0802-\mathrm{B}^{*} 1402\right)$ that appeared to be responsible for the negative relationship between HLA-B14 and the prevalence of NPC in Tunisians. However, the most striking negative association was observed between the HLA-B* $1402 / \mathrm{Cw}^{*} 0802$ haplotype and the prevalence of $\mathrm{NPC}(\mathrm{HF}=0.007$ in patient with NPC compared to a HF of 0.037 in Tunisians and 0.040 in Moroccans). In particular, all the HLA-Cw*08 alleles were identified by SBT as HLA-Cw*0802 while HLA-B14, split this haplotype into 3 sub-haplotypes in which HLA-B*1402 occurred 11 times $(\mathrm{HF}=0.037)$ and HLA-B*1401 and $\mathrm{B}^{*} 1403$ three times each (none of them seen in patients with NPC).

There was a trend toward an age distribution bias with the HLA class I loci associated with NPC predisposition occurring more frequently in the younger age bracket ( $<25$ yearold patients). In particular, HLA-Cw*0602 was present at a frequency of $44 \%$ (14 of 32) in 25 year old or younger NPC patients compared to $16 \%$ ( 6 of 37 ) in patients who had NPC diagnosed after the age of 50 (Fisher test p2value $=0.02)$. Similarly the HLA-B*5701/Cw*0602 haplotype was present in $12 \%$ of cases below age $25,6 \%$ of cases between 25 and 50 and only 3\% of cases above age 50. This trend was, however, not significant possibly because of to the relatively small number of cases. Interestingly, HLA-Cw*0602 and its extended haplotype HLA$\mathrm{B}^{*} 5701 / \mathrm{Cw}^{*} 0602$ were particularly frequent among young patients. Of 11 patients age 16 or younger, 7 (64\%) carried the HLA-Cw*0602 allele and 4 the extended haplotype $(37 \%)$ compared to a frequency of $25 \%$ and $4 \%$ respectively in the older patients (Fisher's exact test $\mathrm{p}_{2}$ value $=0.01$ and 0.003 respectively). Interestingly, the same haplotype was totally absent in the same age group and it occurred only in one case among the 148 control subjects studied. Thus, it is possible that this haplotype may include a predisposition factor that may bear a particular influence on the penetrance of NPC before other environmental factors could contribute to the onset of NPC in later age groups.

\section{Discussion}

NPC is among common cancers the one whose prevalence is most likely affected by a genetic predisposition that can be uncovered through population studies. This seems to particularly apply to the Southern Asian population repeatedly shown to be affected at high incidence. Although viral and environmental factors play an important role in the ethio-pathogenesis of NPC, genetic factors may also predispose as documented by several family and/or case-control studies [45,46]. The short arm of the human chromosome 6 , is not the only genomic area that has been implicated in NPC predisposition as a large family study located a predisposition area in chromosome 3 [3]. However, many case-control studies pointed at HLA class I as a genomic region strongly associated with the prevalence of NPC in Southern Chinese [5-12,47-49] Such associations may bear two possible explanations; first the antigen presenting function of HLA molecules may be responsible for an altered effectiveness of the immune response against tumor associated antigens expressed by NPC in individuals bearing different HLA alleles [10]. This logical explanation is, however, challenged by the lack of candidate epitopic determinants associated to particular HLA class I alleles that clearly affect the natural history of NPC. In addition, most HLA class I associations reported in Asian populations indirectly support this concept since they are primarily associated with increased risk of developing NPC. This suggests that lack of antigen presenting capacity may result in reduced protection against the growth of NPC. For instance, the HLA-A*0207 allele association reported by Hildesheim et al. [10] in Taiwanese Chinese was explained by suggesting a reduced antigen presentation potential of this allele compared with other HLA-A*02 alleles present in the same population such as HLA$A^{*} 0201$ which are not associated with higher prevalence of NPC. Similarly, the higher prevalence of HLA-A*0207 in Asians compared to Caucasians [10] may also explain the higher prevalence of the disease in Asian populations. However, associations of HLA phenotypes with increase prevalence of NPC are difficult to attribute to a single 
Table 5: Comparison of the most common (frequency $>2 \%$ ) HLA-A/B, Cw/B and A/Cw two-loci haplotypes in Tunisians, Tunisian NPC patients and in ME

\begin{tabular}{|c|c|c|c|c|c|c|c|c|c|c|c|c|c|}
\hline \multirow[t]{2}{*}{ Haplotype } & \multicolumn{5}{|c|}{ TUNISIANS } & \multicolumn{5}{|c|}{ NPC TUNISIANS } & \multicolumn{3}{|l|}{ ME } \\
\hline & $\mathrm{HF}$ & $D \times 100$ & $D^{\prime}$ & $\chi^{2}$ & $P$ & $\mathrm{HF}$ & $D \times 100$ & $D^{\prime}$ & $\chi^{2}$ & $P$ & $\mathrm{HF}$ & $\chi^{2}$ & $\mathrm{P}$ \\
\hline \multicolumn{14}{|l|}{$A / B$} \\
\hline$A * 020101 \mathrm{~B} * 500 \mathrm{I}$ & 0.045 & 2.20 & 0.20 & 8.9 & $<0.01$ & 0.044 & 2.70 & 0.33 & 16 & $<0.001$ & 0.029 & 3.50 & NS \\
\hline$A^{*} 020101 B^{*} 440201$ & 0.037 & 2.90 & 0.74 & 40.0 & $<0.001$ & $\begin{array}{l}\text { Not } \\
\text { present }\end{array}$ & & & & & 0.022 & 0.24 & NS \\
\hline$A * 230 I B * 500 I$ & 0.030 & 2.00 & 0.29 & 14.0 & $<0.001$ & $(0.011)$ & & & & & $\begin{array}{l}\text { Not } \\
\text { present }\end{array}$ & & \\
\hline$A * 6802 B * 1402$ & 0.023 & 2.00 & 0.41 & 49.0 & $<0.001$ & $\begin{array}{l}\text { Not } \\
\text { present }\end{array}$ & & & & & $(0.015)$ & & \\
\hline$A * 020101 B * 510101$ & 0.020 & 1.10 & 0.25 & 5.1 & $<0.05$ & $(0.018)$ & & & & & $(0.015)$ & & \\
\hline$A * 010101 B * 570101$ & $(0.003)$ & & & & & 0.022 & 1.80 & 0.62 & 23 & $<0.001$ & $(0.015)$ & & \\
\hline$A * 020101 B * 180101$ & $(0.010)$ & & & & & 0.030 & 1.80 & 0.33 & 10 & $<0.01$ & 0.022 & & NS \\
\hline$A^{*} 020101 B^{*} 440301$ & $(0.013)$ & & & & & 0.033 & 1.80 & 0.24 & 7.6 & $<0.01$ & 0.029 & & NS \\
\hline$A * 2902 B * 440301$ & $(0.012)$ & & & & & 0.021 & 1.60 & 0.29 & 15 & $<0.001$ & $\begin{array}{l}\text { Not } \\
\text { present }\end{array}$ & & \\
\hline$A * 3402 B * 080 I$ & $(0.006)$ & & & & & 0.022 & 2.00 & 0.72 & 58 & $<0.001$ & $\begin{array}{l}\text { Not } \\
\text { present }\end{array}$ & & \\
\hline \multicolumn{14}{|l|}{$\mathrm{Cw} / \mathrm{B}$} \\
\hline$C w^{*} 070 \mathrm{I} \mathrm{B}^{*} 080 \mathrm{I}$ & 0.047 & 3.90 & 0.70 & 68.00 & $<0.001$ & 0.056 & 4.40 & 0.75 & 58 & $<0.001$ & 0.089 & 55.97 & $<0.001$ \\
\hline $\mathrm{CW}^{*} 040101 \mathrm{~B} * 4403$ & $(0.016)$ & & & & & 0.047 & 3.50 & 0.45 & 36 & $<0.001$ & 0.081 & 31.17 & $<0.001$ \\
\hline$C w^{*} 0602$ B*500I & 0.120 & 9.10 & 0.84 & 120.00 & $<0.001$ & 0.081 & 6.20 & 0.77 & 76 & $<0.001$ & 0.073 & 42.62 & $<0.001$ \\
\hline$C w^{*} \mid 701,03 B^{*} 4102$ & 0.020 & 1.90 & 1.00 & 120.00 & $<0.001$ & 0.026 & 2.50 & 1.00 & 160 & $<0.001$ & 0.065 & 124.00 & $<0.001$ \\
\hline$C w^{*} 070 I$ B*490I & 0.027 & 2.30 & 1.00 & 57.00 & $<0.001$ & 0.041 & 3.40 & 0.99 & 57 & $<0.001$ & 0.056 & 34.40 & $<0.001$ \\
\hline$C w * 0802$ B*I 402 & 0.037 & 3.40 & 0.67 & 130.00 & $<0.001$ & $(0.007)$ & & & & & 0.040 & 87.08 & $<0.001$ \\
\hline $\mathrm{CW}^{*} 04010 \mathrm{I} \mathrm{B} * 350 \mathrm{I}$ & 0.020 & 1.70 & 0.71 & 30.00 & $<0.001$ & $\begin{array}{l}\text { Not } \\
\text { present }\end{array}$ & & & & & 0.040 & 30.68 & $<0.001$ \\
\hline $\mathrm{Cw}^{*} 0501 \mathrm{~B} * 4402$ & 0.040 & 3.80 & 0.85 & 22.00 & $<0.001$ & $(0.018)$ & 1.70 & 0.53 & 61 & $<0.001$ & 0.040 & 25.79 & $<0.001$ \\
\hline$C W^{*} 050 \mid$ B*180 I & $\begin{array}{l}\text { Not } \\
\text { present }\end{array}$ & & & & & 0.022 & 2.00 & 0.52 & 43 & $<0.001$ & 0.032 & 36.37 & $<0.001$ \\
\hline$C w^{*} 0602$ B*450I & 0.033 & 2.30 & 0.64 & 22.00 & $<0.001$ & $(0.011)$ & 0.81 & 0.67 & 7.8 & $<0.01$ & 0.032 & 13.03 & $<0.001$ \\
\hline$C w^{*} 0702 B^{*} 07020 \mathrm{I}$ & 0.033 & 3.10 & 0.82 & 150.00 & $<0.001$ & $(0.018)$ & 1.80 & 0.97 & 130 & $<0.001$ & 0.025 & 92.21 & $<0.001$ \\
\hline$C w^{*} 0202$ B*44030I & 0.027 & 2.20 & 0.33 & 34.00 & $<0.001$ & $(0.012)$ & & & & & 0.032 & & NS \\
\hline$C w^{*} 1502$ B*510101 & 0.033 & 3.20 & 1.00 & 180.00 & $<0.001$ & 0.044 & 4.10 & 1.00 & 140 & $<0.001$ & $(0.016)$ & & \\
\hline$C W^{*} \mid 601 B * 440301$ & 0.027 & 2.40 & 0.59 & 62.00 & $<0.001$ & 0.022 & 1.90 & 0.51 & 30 & $<0.001$ & $(0.008)$ & & \\
\hline$C w^{*} 1202$ B*52010I & 0.023 & 2.30 & 1.00 & 30.00 & $<0.001$ & 0.030 & 2.90 & 0.89 & 220 & $<0.001$ & $\begin{array}{l}\text { Not } \\
\text { present }\end{array}$ & & \\
\hline $\mathrm{CW}^{*} 04010 \mathrm{I} \mathrm{B} * 530 \mathrm{I}$ & 0.020 & 1.70 & 0.83 & 35.00 & $<0.001$ & 0.037 & 3.20 & 1.00 & 68 & $<0.001$ & $(0.008)$ & & \\
\hline$C W * 120301 \mathrm{~B} * 380 \mathrm{I}$ & 0.020 & 1.90 & 1.00 & 140.00 & $<0.001$ & $(0.018)$ & & & & & $\begin{array}{l}\text { Not } \\
\text { present }\end{array}$ & & \\
\hline $\mathrm{CW}^{*} 0602 \mathrm{~B} * 1302$ & $(0.017)$ & & & & & 0.026 & 2.10 & 1.00 & 30 & $<0.001$ & $\begin{array}{l}\text { Not } \\
\text { present }\end{array}$ & & \\
\hline$C w^{*} 020204$ B*1503 & $(0.014)$ & & & & & 0.033 & 3.20 & 1.00 & 280 & $<0.001$ & $(0.016)$ & & \\
\hline $\mathrm{CW} * 0701 \mathrm{~B} * 180101$ & $\begin{array}{l}\text { Not } \\
\text { present }\end{array}$ & & & & & 0.037 & 2.60 & 0.46 & 21 & $<0.001$ & $(0.008)$ & & \\
\hline$C w * 0602$ B*570101 & $(0.003)$ & & & & & 0.033 & 2.70 & 1.00 & 40 & $<0.001$ & $(0.008)$ & & \\
\hline \multicolumn{14}{|l|}{$\mathrm{A} / \mathrm{Cw}$} \\
\hline 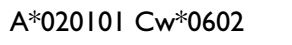 & 0.061 & 2.40 & 0.18 & 7.60 & $<0.01$ & 0.023 & & & & NS & 0.077 & 11.00 & $<0.001$ \\
\hline $\mathrm{A}^{* 030101} \mathrm{CW}^{*} 0602$ & 0.035 & 2.10 & 0.40 & 12.00 & $<0.001$ & 0.033 & 1.90 & 0.32 & 9.4 & $<0.01$ & $\begin{array}{l}\text { Not } \\
\text { present }\end{array}$ & & \\
\hline $\mathrm{A}^{*} 010101 \mathrm{Cw} * 040101$ & 0.033 & 2.20 & 0.29 & 17.00 & $<0.001$ & $(0.007)$ & & & & & $\begin{array}{l}\text { Not } \\
\text { present }\end{array}$ & & \\
\hline 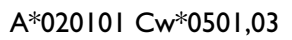 & 0.032 & 2.40 & 0.63 & 28.00 & $<0.001$ & 0.022 & 1.50 & 0.46 & 12 & $<0.001$ & $(0.012)$ & & \\
\hline$A^{*} 2301 \mathrm{Cw}^{*} 0602$ & 0.032 & 1.60 & 0.27 & 6.50 & $<0.05$ & $(0.016)$ & & & & & $\begin{array}{l}\text { Not } \\
\text { present }\end{array}$ & & \\
\hline$A^{*} 010101 C^{*} 0602$ & $\begin{array}{l}\text { Not } \\
\text { present }\end{array}$ & & & & & 0.041 & 1.60 & 0.15 & 3.9 & NS & 0.026 & & NS \\
\hline
\end{tabular}


Table 5: Comparison of the most common (frequency > 2\%) HLA-A/B, Cw/B and A/Cw two-loci haplotypes in Tunisians, Tunisian NPC patients and in ME (Continued)

\begin{tabular}{|c|c|c|c|c|c|c|c|c|c|}
\hline $\mathrm{A}^{* 010101} \mathrm{Cw}^{* 070 \mathrm{I}}$ & 0.023 & NS & 0.037 & 1.60 & 0.14 & 4.2 & NS & $(0.016)$ & \\
\hline$A * 020101 C^{*} * 040101$ & $(0.014)$ & & 0.037 & 1.40 & 0.13 & 3.3 & NS & 0.040 & NS \\
\hline$A * 020101 C_{w}^{*} 0701$ & 0.023 & NS & 0.036 & & & & NS & 0.020 & NS \\
\hline$A^{*} 2902 C^{*} * 1601$ & $(0.010)$ & & 0.022 & 1.90 & 0.52 & 48 & $<0.001$ & $\begin{array}{l}\text { Not } \\
\text { present }\end{array}$ & \\
\hline$A * 3402 C w * 0701$ & $(0.007)$ & & 0.022 & 1.70 & 0.69 & 20 & $<0.001$ & $(0.016)$ & \\
\hline
\end{tabular}

HF: haplotype frequency; SD: standard deviation; Dx 100: linkage disequilibrium multiplied by 100; D': relative linkage disequilibrium; $\chi^{2}$ : chi-square values In bold: alleles involved in NPC. In parenthesis: haplotypes present at low frequency $(<2 \%)$.

allele considering the high frequency of heterozygosity and the co-dominant expression of the three HLA class I loci aimed at broadening the antigen presenting repertoire of each individual.

An alternative explanation for the association between HLA and the prevalence of NPC attributes a broader significance of HLA class I genes as markers for other predisposition factors genetically controlled within a locus in close linkage disequilibrium [21]. For instance, even in Hildesheim's report, the extended haplotype HLAA*0207/HLA-B*4601 was characterized by a higher odds ratio to develop NPC than the HLA-A*0207 allele alone suggesting a more complex genetic explanation for such association than the displacement by the HLA-A*0207 allele of other HLA class I alleles belonging to the HLA$A^{*} 02$ family. In addition, our and others' experiences do not suggest strong differences in epitope binding and antigen presentation between HLA-A*0201 (the prototypic Caucasian HLA-A*02 allele) and HLA-A*0207. These alleles differ only by one amino acid substitution from a Tyrosine to a Cysteine in position 99 within the binding groove of the HLA molecule. This substitution does not seem to significantly affect binding and presentation of canonical HLA-A*0201-associated epitopes [50-52] as well as EBV-associated epitopes [53]. Finally, lack of antigen presentation capacity by a specific HLA class I allele should be compensated by other alleles expressed by the same individual; therefore, favouring homozygosity of the unfavourable allele in affected individuals. However, most reports do not suggest higher homozygosity values in high prevalence populations suggesting lack of balancing selection. Thus, dominant genetic traits directly related to oncogenesis may play a more important role than HLA class I alleles which are co-dominantly expressed.

Maghrebs have been less exhaustively studied. However, serological analyses observed positive associations between NPC and HLA class I alleles. These include increased frequency of HLA-B5 in Algerians (38.2\% vs $24.4 \%$ ) [22], HLA-B13 in Tunisians (15.5\% vs 4) [23] and HLA-B1 8 in Moroccans (relative risk = 4.14) [24]. In addition, negative associations have been reported such as HLA-Aw33, -B14 in Algerians with NPC. However, after correction for the number of specificities tested, these differences were not statistically significant and were not pursued further. HLA-A*3301 and HLA-B*1402 have subsequently been recognized to belong to the same ancestral haplotype [25] suggesting that this haplotype may harbor more relevance to NPC than previously recognized. This impression was supported also by the identification of a negative association between HLA-A23 (known to belong to the extended HLA-A*2301/HLA$\mathrm{B} * 1403$ haplotype [26]) and the prevalence of NPC [23]. This observation converges toward the relevance of HLAB14 related haplotypes which may bear protective effects against NPC in North Africans. Moreover, Dardari R et al. [24] reported a significantly lower frequency of the HLAA9 serologic family alleles in NPC patients compared with controls. Since the latter study did not provide molecular resolution, we can only speculate that the reduced frequency of HLA-A9 reflected a lower frequency of the HLAA*2301/HLA-B*1403 haplotype since HLA-A23 is part of the HLA-A9 serological family. Thus, previous studies in Maghrebians suggested that HLA-B14 and HLA-A alleles linked to the HLA-B14 serological family may be underrepresented in patients with NPC compared with normal controls. Conversely, HLA-B5, -B13 and -B18 could be associated with increased risk of NPC.

Low resolution (two digits level) analysis of allele frequency in our study quite remarkably and specifically confirmed previous positive associations described between NPC and HLA class I alleles in Berber populations. Both HLA-B* 18 and $-\mathrm{B}^{*} 51$ (the latter representing a split of the serologically-defined HLA-B5 family) were confirmed by our study (Table 4). In addition, a novel association was observed between HLA-B-57 (belonging to the HLA-B17 serological family) and the prevalence of NPC. Only the positive association observed in Tunisians between HLA-B13 and NPC prevalence was not reproduced by this study [23]. Negative associations were also identified by this study of which only HLA-B*14 (OR = 0.09 , Fisher's test $\mathrm{p}-2$ value $=0.0001$ ) strongly reproduced previous findings while no association was noted with HLA-A*23 nor HLA-A*33. Interestingly, however, another strong negative association was noted between HLA-Cw*0802 and NPC $(\mathrm{OR}=0.18$, Fisher's test $\mathrm{p}-2$ value $=0.003)$. This is of particular significance because 
both HLA-B*1402 and HLA-Cw*0802 belong to the same ancestral haplotype which was present not only in Tunisians but also Moroccan Berbers but practically absent in Tunisian patients with NPC (OR $=0.12$, Fisher's test $\mathrm{p}-2$ value $=0.001)$. This strong negative association suggests that this haplotype may bear a locus in strong linkage disequilibrium with these HLA alleles with dominant protective effects against the onset of NPC in North Africans such as a tumor suppressor gene with stronger stability in this phenotype. Since protective alleles have also been described in Asian populations (such as HLA-A11) [13], it could be postulated that some HLA alleles may bear immunological functions facilitating the immune surveillance against NPC. However, there is no known functional similarity between alleles described in Chinese and North Africans to support this hypothesis suggesting that other factors may bear on this predisposition. Indeed, in Asian populations, micro-satellite analyses within the short arm of Chromosome 6 identified associations between putative loci and NPC prevalence that are stronger than those with HLA class I alleles [12]. Hu C-C et al. [54] using high-resolution micro satellite mapping recently described a carcinoma-susceptibility locus located in a segment of Chromosome 6p21.3 containing the class I loci. Similarly, Nh SP et al. [55] concluded that an HLA-related recessive mutation is responsible for the prevalence of NPC in Chinese. Finally, Tian W et al. [56] identified in the Southern Chinese Han population a positive association between a predisposition to develop NPC and exon 5 of the MICA-STR encoded within the HLA class I region. Moreover, a recent meta-analysis of chromosomal aberrations associated with NPC [57] identified a small region in Chromosome 6p21.2-p23 that is frequently amplified in NPC and contains various candidate genes that may be responsible for NPC [58]. Thus, our findings suggest that there are haplotypes within or close to HLA class I region, particularly the HLA-B and -C loci that may bear genetic characteristics favoring or protecting against the onset of NPC in Tunisian populations at risk. This information may help identify individuals belonging to different ethnic groups whose genetic risk to develop NPC could be marked by HLA class I haplotypes. These prototypic phenotypes could be scanned with novel high throughput technologies covering genomic areas in high linkage disequilibrium with such haplotypes. Since the analysis of the Tunisian control population did not identify differences between Tunisians and Moroccans, considering that a common Berber substratum is shared by North African countries [59-63], it is possible that our findings could be relevant to the other Northern African populations justifying the extension of future studies to Moroccans and Algerians [24].

Some of the alleles discussed by this study have been associated with other pathologies. HLA-B*1403 is the pre- dominant allele in patients affected by ankylosing spondylitis from West Africa, where HLA-B*27 is uncommon [64]. HLA-B*51 and HLA-B* 15 alleles have been associated with Behcet disease [65], B*44, B*51, B*57, $\mathrm{B}^{*} 15$ with HPV infection and protection/susceptibility to in cervical carcinoma [66]. The present study, may offer novel insight on the molecular genetics of this region that may influence disease, although obvious relationships between the information presented and it causality is still missing.

\section{Acknowledgements}

The authors wish to thank Dr. Khadija Oumhani and Prof. Rajae El Aouad for their precious contribution with the study of the original Moroccan samples.

\section{References}

I. Khlat M: Cancer in Mediterranean migrants - based on studies in France and Australia. Cancer Causes Control 1995, 6:525-531.

2. Bouchardy C, Parkin DM, Wanner P, Khlat M: Cancer mortality among north African migrants in France. Int J Epidemiol 1996, 25:5-13.

3. Feng BJ, Huang W, Shugart YY, Lee MK, Zhang F, Xia JC, Wang HY, Huang TB, Jian SW, Huang P, et al.: Genome-wide scan for familial nasopharyngeal carcinoma reveals evidence of linkage to chromosome 4. Nat Genet 2002, 31:395-399.

4. Chan AT, Teo PM, Huang DP: Pathogenesis and treatment of nasopharyngeal carcinoma. Semin Oncol 2004, 3 I:794-80I.

5. Jing J, Louie E, Henderson BE, Terasaki IP: Histocompatibility leukocyte antigen patterns in nasopharyngeal carcinoma cases from California. Natl Cancer Inst Monogr 1977, 47:156.

6. Cui SH, Lin Y: Apparent correlation between nasopharyngeal carcinoma and HLA phenotype. Zhong Hua Zhong Liu Zhi 1982, 4:249-253.

7. Chan SH, Day NE, Kunaratnam N, Chia KB, Simons MJ: HLA and nasopharyngeal carcinoma in Chinese - a further study. Int J Cancer 1983, 32:17|-176.

8. Ou B-X, Ruan H-Y, Fan Y: Study on association between HLAA, B, C DR, and nasopharyngeal carcinoma in Guangzhou area. Ai Zheng 1985, 4:5-8.

9. Zhang JZ: Correlation between nasopharyngeal carcinoma (NPC) and HLA in Hunan Province. Zhong Hua Zhong Liu Zhi 1986, 8: $170-172$.

10. Hildesheim A, Apple RJ, Chen C-J, Wang SS, Cheng Y-J, Klitz W, Mack SJ, Chen IH, Hsu MM, Yang CS, Brinton LA, Levine PH, Erlich HA: Association of HLA class I and II alleles and extended haplotypes with nasopharyngeal carcinoma in Taiwan. J Natl Cancer Inst 2002, 94:1780-1789.

II. Pimtanothai N, Charoenwongse P, Mutirangura A, Hurley CK: Distribution of HLA-B alleles in nasopharyngeal carcinoma patients and normal controls in Thailand. Tissue Antigens 2002, 59:223-225.

12. Lu C-C, Chen J-C, Jin Y-T, Yang H-B, Chan S-H, Tsai S-T: Genetic susceptibility to nasopharyngeal carcinoma within the HLAA locus in Taiwanese. Int J Cancer 2003, 103:745-75 I.

13. Goldsmith DB, West TM, Morton R: HLA associations with nasopharyngeal carconoma in Southern Chinese: a metaanalysis. Clin Otolaryngol 2002, 27:6I-67.

14. Krausa P, Browning MJ: A comprehensive PCR-SSP typing system for identification of HLA-A locus alleles. Tissue Antigens 1996, 47:237-244.

15. Marsh SG, Albert ED, Bodmer WF, Bontrop RE, Dupont B, Erlich HA, Geraghty DE, Hansen JA, Mach B, Mayr WR, Parham P, Petersdorf EW, Sasazuki T, Schreuder GM, Strominger JL, Svejgaard A, Terasaki $\mathrm{PI}$ : for factors of the HLA system, 2002. Eur J Immunogen 2002, 29:463-515.

16. Krausa P, Brywka M, Savage D, Hui KM, Bunce M, Ngai JL, Teo DL, Ong YW, Barouch D, Allsop C: Genetic polymorphism within HLA-A*02: significant allelic variation revealed in different populations. Tissue Antigens 1995, 45:223-231. 
17. Browning M, Krausa P: Genetic diversity of HLA-A2: evolutionary and functional significance. Immunol Today 1996, I 7: I65-I70.

18. Simonis TB, Barracchini KC, Hackett JA, Maurer D, Siauw P, Tonai R: HLA-A*02 allele frequencies of different ethnic groups. Hum Immunol 1997, 55:99.

19. Chang YW, Hawkins BR: HLA class I and class II frequencies of a Hong Kong Chinese population based on bone marrow donor registry data. Human Immunol I997, 56: I 25-I 35.

20. Clamp M, Andrews D, Barker D, Bevan P, Cameron G, Chen Y, Clark L, Cox T, Cuff J, Curwen V, et al.: Ensembl 2002: accommodating comparative genomics. Nucleic Acids Res 2003, 31 :38-42.

21. Simons MJ: HLA and nasopharyngeal carcinoma: 30 years on. ASHI Quarterly 2003, 27:52-55.

22. Herait P, Tursz T, Guillard MY, Hanna K, Lipinski M, Micheau C, Sancho-Garnier H, Schwaab G, Cachin Y, Degos L: HLA-A, -B, and DR antigens in North African patients with nasopharyngeal carcinoma. Tissue Antigens 1983, 22:335-34I.

23. Mokni-Baizig N, Ayed K, Ayed FB, Ayed S, Sassi F, Ladgham A, Bel Hadj O, El May A: Association between HLA-A/-B antigens and -DRBI alleles and nasopharyngeal carcinoma in Tunisia. Oncology 200I, 6 I:55-58.

24. Dardari R, Khyatti M, Jouhadi $H$, Benider A, Ettayebi $H$, Kahlain A, Mansouri A, El Gueddari B, Benslimane A: Study of human leukocyte antigen class I phenotypes in Moroccan patients with nasopharyngeal carcinoma. Int J Cancer 200I, 92:294-297.

25. Williams F, Meenagh A, Darke C, Acosta A, Daar AS, Gorodezky C, Hammond M, Nascimento E, Middleton D: Analysis of the distribution of HLA-B alleles in populations from five continents. Hum Immunol 200 I, 62:645-650.

26. Ellis JM, Mack SJ, Leke RF, Quakyi I, Johnson AH, Hurley CK: Diversity is demonstrated in class I HLA-A and HLA-B alleles in Cameroon, Africa: description of HLA-A*0 $* 2612, * 3006$ and HLA-B*I403, *40 I6, *4703. Tissue Antigens 3012, 56:291-302.

27. Sanchez-Mazas A, Steiner QG, Grundschober C, Tiercy JM: The molecular determination of HLA-Cw alleles in the Mandenka (West Africa) reveals a close genetic relationship between Africans and Europeans. Tissue Antigens 2000, 56:303-312.

28. Piancatelli D, Canossi A, Aureli A, Oumhani K, Del Beato T, Di Rocco M, Liberatore G, Tessitore A, Witter K, El Aouad R, Adorno D: Human leukocyte antigen-A, $-B$, and $-C w$ polymorphism in a Berber population from North Morocco using sequencebased typing. Tissue Antigens 2004, 63:158-I72.

29. Cao K, Moormann AM, Lyke KE, Masaberg C, Sumba OP, Doumbo OK, Koech D, Lancaster A, Nelson M, Meyer D, Single R, Hartzman RJ, Plowe CV, Kazura J, Mann DL, Sztein MB, Thomson G, FernandezVina MA: Differentiation between African populations is evidenced by the diversity of alleles and haplotypes of HLA class I loci. Tissue Antigens 2004, 63:293-325.

30. Shanmugaratnam K, Tye CY, Goh EH, Chia KB: Etiological factors in nasopharyngeal carcinoma: a hospital-based, retrospective, case-control, questionnaire study. IARC Sci Publ 1978:199-212.

31. Shanmugaratnam K, Sobin LH: World Health Organization. International Histological Classification: Histological typing of tumors of the upper respiratory tract and ear 2nd edition. Berlin: Springer-Verlag; 1991.

32. Adams SD, Barracchini KC, Chen D, Robbins F, Wang L, Larsen $P$, Luhm R, Stroncek DF: Ambiguous allele combinations in HLA Class I and Class II sequence-based typing: when precise nucleotide sequencing leads to imprecise allele identification. J Transl Med 2004, 2:30.

33. Guo SW, Thompson EA: Performing the exact test of HardyWeinberg proportion for multiple alleles. Biometrics 1992 48:361-372

34. Arlequin Population Software [http://cmpg.unibe.ch/software/
(n) arlequin3].

35. Excoffier L, Laval LG, Schneider S: Arlequin ver 3.0: An integrated software package for population genetics data analysis. Evol Bionformatics On Line 2005, I:47-50.

36. Ewens WJ: The sampling theory of selectively neutral alleles. Theor Popul Biol 1972, 3:87-I I 2.

37. Watterson GA: The homozygosity test of neutrality. Genetics | 978, 88:405-4|5.

38. Slatkin M: An exact test for neutrality based on the Ewens sampling distribution. Genet Res 1994, 64:7|-74.
39. Slatkin M: A correction to the exact test based on the Ewens sampling distribution. Genet Res 1996, 68:259-260.

40. Imanishi T, Azaka T, Kimura A, Tokunaga K, Gojobori T: Estimation of allele and haplotype frequencies for HLA and complement loci. In HLA 199/ Edited by: Tsuji K, Aizawa M, Sesazuki T. Oxford: Oxford University Press; 1992.

4l. NPDP Bioinformatics [http://bioinformatics.nmdp.org]

42. Allele frequencies in worldwide populations 2007 [http://www.allelefre quencies.net].

43. Cao K, Hollenbach J, Shi X, Shi W, Chopek M, Fernandez-Vina MA: Analysis of the frequencies of HLA-A, B, and $C$ alleles and haplotypes in the five major ethnic groups of the United States reveals high levels of diversity in these loci and contrasting distribution patterns in these populations. Hum Immunol 2001, 62:1009-1030.

44. Daoud J, Toumi N, Bouaziz M, Ghorbel A, Jlidi R, Drira MM, Frikha $M$ : Nasopharyngeal carcinoma in childhood and adolescence: analysis of a series of 32 patients treated with combined chemotherapy and radiotherapy. Eur J Cancer 2003, 39:2349-2354.

45. Chan ATC, Teo PML, Johnson PJ: Nasopharyngeal carcinoma. Ann Oncol 2002, I3:1007-1015.

46. McDermott AL, Dutt SN, Watkinson JC: The aetiology of nasopharyngeal carcinoma. Clin Otolaryngol 200I, 26:82-92.

47. Simons MJ, Day NE, Wee GB, Shanmugaratnam K, Ho HC, Wong SH, Ti TK, Yong NK, Darmalingam S, De-The G: Nasopharyngeal carcinoma V: immunogenetic studies of Southeast Asian ethnic groups with high and low risk for the tumor. Cancer Res 1974, 34: I192-1195.

48. Yuan BW: Correlation between nasopharyngeal carcinoma and HLA in Sichuan. Zhonghua Zhong Liu Za Zhi 1988, I 0:263-266.

49. Pimtanothai N, Kangwanshiratada O, Charoenwongse P: Serological analysis of human leukocyte antigens-A and -B antigens in Thai patients with nasopharyngeal carcinoma. J Med Assoc Thai 2003, 86:S237-S24I.

50. del Guercio MF, Sidney J, Hermanson G, Perez C, Grey HM, Kubo RT, Sette A: Binding of a peptide antigen to multiple HLA alleles allows definition of an A2-like supertype. J Immunol 1995, I 54:685-693.

5I. Rivoltini L, Loftus DJ, Barracchini K, Arienti F, Mazzocchi A, Biddison WE, Salgaller ML, Appella E, Parmiani G, Marincola FM: Binding and presentation of peptides derived from melanoma antigens MART-I and gp 100 by HLA-A2 subtypes: implications for peptide-based immunotherapy. J Immunol 1996, I 56:3882-389I.

52. Bettinotti $M$, Kim Cl, Lee K-H, Roden M, Cormier JN, Panelli M, Parker KK, Marincola FM: Stringent allele/epitope requirements for MART-I/Melan A immunodominance: implications for peptide-based immunotherapy. I Immunol 1998 , | 6 | :877-889.

53. Provenzano M, Selleri S, Jin P, Wang E, Werden R, Slezak S, Adams SD, Panelli MC, Leitman SF, Stroncek DF, Marincola FM: Comprehensive epitope mapping of the Epstein-Barr virus latent membrane protein-2 in normal, non tumor-bearing individuals. Cancer Immunol Immunother 2006

54. Lu CC, Chen JC, Tsai ST, Jin YT, Tsai JC, Chan SH, Su IJ: Nasopharyngeal carcinoma-susceptibility locus is localized to a 132 kb segment containing HLA-A using high-resolution microsatellite mapping. Int J Cancer 2005, I I 5:742-746.

55. Hu SP, Day NE, Li DR, Luben RN, Cai KL, Ou-Yang T, Li B, Lu XZ, Ponder BA: Further evidence for an HLA-related recessive mutation in nasopharyngeal carcinoma among the Chinese. Br J Cancer 2005, 92:967-970.

56. Tian W, Zeng XM, Li LX, Jin HK, Luo QZ, Wang F, Guo SS, Cao Y: Gender-specific associations between MICA-STR and nasopharyngeal carcinoma in a southern Chinese Han population. Immunogenetics 2006, 58: II3-I2I.

57. Li X, Wang E, Zhao YD, Ren JQ, Jin P, Yao KT, Marincola FM: Chromosomal imbalances in nasopharyngeal carcinoma: a metaanalysis of comparative genomic hybridization results. Transl Med 2006, 4:4.

58. Jalbout M, Bouaouina N, Gargouri J, Corbex M, Ben Ahmed S, Chouchane L: Polymorphism of the stress protein HSP70-2 gene is associated with the susceptibility to the nasopharyngeal carcinoma. Cancer Lett 2003, I93:75-8I. 
59. Bosch E, Calafell F, Perez-Lezaun A, Comas D, Mateu E, Bertranpetit J: Population history of north Africa: evidence from classical genetic markers. Hum Biol 1997, 69:295-3II.

60. Chaabani H, Cox DW: Genetic characterization and origin of Tunisian Berbers. Hum Hered 1988, 38:308-316.

61. Gomez-Casado E, del Moral P, Martinez-Laso J, Garcia-Gomez A, Allende L, Silvera-Redondo C, Longas J, Gonzalez-Hevilla M, Kandil M, Zamora J, Arnaiz-Villena A: HLA genes in Arabic-speaking Moroccans: close relatedness to Berbers and Iberians. Tissue Antigens 2000, 55:239-249.

62. Lucotte G, Aouizerate A, Berriche S: Y-chromosome DNA haplotypes in North African populations. Hum Biol 2000, 72:473-480.

63. Myles S, Bouzekri N, Haverfield E, Cherkaoui M, Dugoujon JM, Ward $\mathrm{R}$ : Genetic evidence in support of a shared Eurasian-North African dairying origin. Hum Genet 2005, 1 1 7:34-42.

64. Lopez-Larrea C, Mijiyawa M, Gonzalez S, Fernandez-Morera JL, Blanco-Gelaz MA, Martinez-Borra, Lopez-Vazquez A: Association of ankylosing spondylitis with HLA-B*1403 in a West African population. Arthritis Rheum 2002, 46:2968-297I.

65. Choukri F, Chakib A, Himmich H, Marih L, Caillat-Zucman S: HLA$B$ phenotype modifies the course of Behcet's disease in Moroccan patients. Tissue Antigens 2003, 61:92-96.

66. Zehbe I, Mytilineos J, Wikstrom I, Henriksen R, Edler L, Tommasino M: Association between human papillomavirus 16 E6 variants and human leukocyte antigen class I polymorphism in cervical cancer of Swedish women. Hum Immunol 2003, 64:538-542.

Publish with Bio Med Central and every scientist can read your work free of charge

"BioMed Central will be the most significant development for disseminating the results of biomedical research in our lifetime. "

Sir Paul Nurse, Cancer Research UK

Your research papers will be:

- available free of charge to the entire biomedical community

- peer reviewed and published immediately upon acceptance

- cited in PubMed and archived on PubMed Central

- yours - you keep the copyright

Submit your manuscript here:

http://www.biomedcentral.com/info/publishing_adv.asp
BioMedcentral 